ten winst extra in den verkoopprijs. Dan komt, hoe vreemd het ook klinkt, een ander element: de liquiditeitspositie, als prijsvormende factor naar voren.

Doch dit zijn extreme gevallen - er zijn nog vele gevallen, waarin een calculatie van den verkoopprijs op basis van vervangingswaarde wel mogelijk zou zijn.

Van bedrijfshuishoudkundig standpunt bezien is dan de vraag, wat het juiste uitgangspunt is bij het vaststellen van den prijs, niet moeilijk te beantwoorden, ook al zou van het ,,vullen van reservoirs tijdelijk geen sprake kunnen zijn en de calculatie bij het ontbreken van betrouwbare prijs-gegevens uiterst moeilijk zijn.

Bezien van het standpunt der Overheid, die voorschriften voor prijsvorming moet geven, speelt echter niet alleen het ondernemingsbelang een rol hoe belangrijk dit ook van sociaal-economisch standpunt bezien, is.

Bij het uitvaardigen van de tegenwoordige Prijsvoorschriften moest allereerst de uitwerking op de prijsstijging voor oogen staan en voor- en nadeelen van voorschriften tegen elkaar worden afgewogen.

Het is duidelijk, dat het calculeeren op basis van vervangingswaarde het tijdstip voor verhooging van prijzen voor eindproducten vervroegt en deze meer algemeen maakt. Dit alles is zeker niet in overeenstemming met het doel der Prijsvoorschriften.

Houdt men dan nog rekening met de argumenten, welke aangevoerd kunnen worden tegen een calculatie op basis van vervangingswaarde in deze tijden, dan is het dus niet te verwonderen, dat het calculeeren van den verkoopprijs op basis van vervangingswaarde niet toegestaan is, doch de historische kostprijs uitgangspunt moet zijn voor het becijferen van den verkoopprijs, afgezien van een enkel uitzonderingsgeval.

Het argument, dat de ondernemer, indien hij niet met vervangings waarde calculeert, weliswaar in finantiëele moeilijkheden zal kunnen komen, doch zich daaruit door het opnemen van credieten kan redden, kunnen wij niet laten gelden. Het gaat niet aan, prijzen te drukken, omdat een ondernemer toch wel een uitweg zal vinden!

Geen ondernemer zal dit argument als redelijk kunnen aanvaarden - wel is begrip te verwachten voor sociale overwegingen, indien ook het bestaan van goed gefundeerde ondernemingen daarbij als sociaal belang in rekening gebracht is.

Overleg met het bedrijfsleven kan veel misverstand ten aanzien van de Prijsvoorschriften voorkomen of uit den weg ruimen en tot een redelijke uitvoering leiden. Hier ligt m.i. een belangrijke taak voor de $\mathrm{Be}$ drijfsorganisaties.

\title{
DE FUNCTIE EN DE ARBEID VAN DEN RIJKSACCOUNTANT
} door J. H. Hageman

In het April No. van dit Maandblad komt de Heer Nije terug op het antwoord van mijne collega's en mij naar aanleiding van het Arrest B.i.B. 6782. Aan het slot noodigt hij de rijksaccountants uit ook hunne meening te geven over het verschil in functie van den public accountant en den accountant beambte.

Eigenlijk gezegd dacht ik eerst niet aan die uitnoodiging gevolg te 
geven, te meer niet toen ik hoorde dat de Heer Westra bereids de handschoen had opgenomen. Hiervoor had ik twee redenen: ten eerste had ik het idee dat zulk een discussie allicht een bij uitstek theoretische wending zou nemen.

De andere reden was dat men over hetgeen mij op het hart lag eigenlijk beter eens in kleine kring kan praten dan er in een tijdschrift een artikel over schrijven.

Ten slotte meende ik dat ik het maar eens moest wagen eene uiteenzetting te geven van de functie van den rijksaccountant en diens arbeid, zooals ik die zie. Ik ging hier te eerder toe over omdat zijn artikelen blijk geven van een total gemis van inzicht in de ambtelijke verhoudingen en de groote vrijheid die de ambtenaar geniet zijn taak naar eigen inzicht te verrichten, terwijl hij naar mijne meening evenmin een juiste voorstelling heeft van de taak van den rijksaccountant, van de omstandigheden waaronder hij heeft te werken en van de moeilijkheden die hij daarbij ondervindt.

Ik zal daarbij het artikel niet op den voet volgen al zal ik er wel van tijd tot tijd naar verwijzen, terwijl ik verschillende zijner bezwaren niet zal behandelen, daar mij dit te ver zou voeren.

Blijkens het eerste deel van het artikel gaat de Heer Nije er van uit dat het accepteeren van onderzoeken met een beperkte doelstelling deze afschuwelijke term is mij inderdaad ontglipt - alleen kan geschieden als men ambtenaar is en dus heeft te gehoorzamen en dat een public accountant, die immers onafhankelijk is, dit niet zou mogen doen en trekt daaruit zijn conclusies.

Dit uitgangspunt is echter totaal onjuist zoowel historisch als practisch. Zijne meening is echter begrijpelijk, want het is voor een buitenstaander niet gemakkelijk een juist inzicht te verkrijgen in de ambtelijke verhoudingen. Er is nu eenmaal niets dat zoo moeilijk te bestrijden is als een legende en zoo is het met de legende van de ambtelijke sleur en de ambtelijke gebondenheid aan allerlei voorschriften en reglementen.

Thans zegt de Heer Nije dat de accountant ambtenaar niet vrij is. omdat men hem van hooger hand voorschrijft in hoeveel tijd en hoe hij zijn onderzoek heeft te verrichten. Indien hij hiermede bedoelt, dat zij en de adjunct-accountants onder leiding werken van een Hoofd van Bureau heeft hij gelijk. In de particuliere praktijk is het echter niet anders.

Doch het is een vergissing te meenen dat hem en hiermede bedoel ik ook den adjunct-accountant geen initiatief wordt gelaten. Het is juist zoo, dat de ambtenaren van den buitendienst in het algemeen een buitengewoon groote vrijheid hebben hun werk volgens eigen inzicht te verrichten, mits zij bereid zijn de verantwoordelijkheid er voor te dragen. Het Departement verwacht dat een Hoofd van een Bureau en zeker het Hoofd van een Dienst de verantwoordelijkheid voor het te verrichten werk op zich kan en op zich durft nemen en men is doordrongen van het feit dat dit hem niet mogelijk zou zijn, wanneer men hem al te veel aan banden zou leggen.

Men zal echter vragen hoe komt men dan aan deze legende. Het is zoo, een legende heeft steeds een zekere kern van waarheid, maar door haar te veralgemeenen wordt ze een leugen. Het gevaar van het ambtenaar zijn is nu eenmaal dat velen gaarne de verantwoordelijkheid van zich afschuiven, zich normen scheppen en zich daarachter dekken en verschuilen. Dat kan op den duur leiden tot een geweldige sleur, het ge- 
bruiken van concepten voor alles en nog wat. Ik zou niet graag beweren dat die geestesgesteldheid zich bepaalt tot ambtenaren.

Ik kan echter verklaren dat, indien men verantwoordelijkheid weet te dragen, men als ambtenaar een zeer groote mate van onafhankelijkheid bezit en alle gelegenheid heeft het werk, waarvoor men staat, naar eigen inzicht te verrichten. Dat dit alles dan ook verantwoord moet zijn spreekt natuurlijk van zelf.

Indien het werk van den Rijksaccountant dan ook geschiedt zooals het geschiedt, is dit omdat de Rijksaccountants in de practijk hebben ervaren dat zij op deze manier, het beste resultaat bereikten. Dat de Belasting Administratie en de Inspecteurs in het bijzonder het over het algemeen hiermede eens waren, bleek doordat zij steeds meer zaken ter onderzoek hebben gezonden en dat de Dienst deswege een steeds grootere uitbreiding verkreeg.

Ook de historie leert dat men bij de invoering der Wet op de Inkomsten-Belasting 1914 nog niet dacht aan een gebruik maken van accountants, laat staan aan de kwestie of deze zich zouden moeten bepalen tot een beperkt of een uitgebreid onderzoek. Ik ben het volkomen met den Heer de Blaey eens dat men waarschijnlijk alleen aan zeer summiere inzage dacht.

De tijd gaat zoo snel dat men tegenwoordig vergeten is dat 25 jaar geleden het bekende;

\section{Komt vrij op mijn kantoor \\ En kijk in alle hoeken \\ Maar neuzen uit de kast \\ En oogen uit de boeken}

nog niet zoo absoluut in onbruik was als thans wel het geval is, dat men toen nog tegenkwam geheimboeken, bijgehouden door den patroon zelf en waarvan de inhoud ook werkelijk een geheim was voor een ieder buiten hem.

Het sprak dan ook volstrekt niet van zelf dat de verplichting tot het geven van inzage van boeken en bescheiden in de wet werd opgenomen.

In de Kamer was de oppositie er tegen sterk en de betreffende artikelen werden slechts met kleine meerderheid aangenomen, nadat bij amendement in art. 70 de verplichting tot het verleenen van boekinzage voor degenen die niet verplicht waren boek te houden was geschrapt, terwijl den volgenden dag slechts met een kleine meerderheid een soortgelijk amendement op art 74 , betrekking hebbende op de boekinzage bij reclame, werd verworpen.

Het spreekt van zelf dat deze geheel nieuwe bevoegdheid - onder de Wet op de Bedrijfsbelasting kon de Inspecteur en de Raad van Beroep wel inzage vragen van de balans, maar als men weigerachtig was niet eischen, terwijl zoowel het recht tot navordering, als de verhoogde aanslag bij niet geslaagd beroep onbekend waren - onder deze omstandigheden slechts met voorzichtigheid moest worden gehanterd. Slechts in bijzondere omstandigheden moest volgens Ministerieele Missive van deze bevoegdheid gebruik worden gemaakt. Fict gebruiknaken van de diensten van Accountants, waarbij in den beginne nog in het midden werd gelaten of dit ambtenaren zouden zijn, dan wel accountants, of deskundigen uit het vrije beroep, werd pas overwogen bij de invoering van de Oorlogswinstbelasting. 'Toen eindelijk in 1916 twee. zegge twee, accountants voor het geheele land waren aangesteld, kon het ge- 
beuren dat zij gedurende eenige maanden nog volstrekt geen werk hadden. Eerst later, toen het effect hunner bemoeiïngen uiteraard bleek. kwam het werk los en werd overgegaan tot steeds grootere uitbreiding van den dienst.

Uit een en ander blijkt overtuigend dat de geheele inrichting van den dienst en de groote bevoegdheden, die in den loop der jaren de Rijks. accountants verkregen door steeds ruimere interpretatie van de bekende artikelen in de Wet I.B. door den Hoogen Raad niet het gevolg waren van een te voren wel overwogen plan van de Regeering, maar de sanctioneering van het inzicht en het initiatief van de Accountants in die. jaren.

Op gelukkige wijze zijn deze er in geslaagd op grond van hunne vaktechnische inzichten den Dienst zoodanig op te zetten dat zoowel zijn inwendige organisatie als de over het algemeen gevolgde werkwijze in groote trekken tot op heden ongewijzigd zijn gebleven.

Uiteraard is het duidelijk dat meeningsverschil dienaangaande mogelijk is, doch ik meen te mogen constateeren dat men volkomen op den verkeerden weg is, indien men meent dat den rijksaccountant geen onafhankelijkheid is gelaten en dat hij slechts het initiatief heeft, dat de leider hem wenscht te laten en dat zijn taak wordt bepaald door diens inzichten.

Iemand die zijn taak zoo zou zien is niet geschikt voor de functie van rijksaccountant, die zonder initiatief en zonder moed verantwoordelijkheid te dragen er niet in zal slagen zijn ambt naar behooren te vervullen.

Op grond van een en ander meen ik daarentegen dat als men de functie van den rijksaccountant en de wijze waarop hij zijn arbeid pleegt te verrichten wil beoordeelen, men allereerst zal hebben te letten op de taak die hij heeft te verrichten en op de omstandigheden waaronder hij arbeidt.

Alvorens hiertoe over te gaan, zou ik op een paar punten willen wijzen die daarbij naar mijne meening van belang zijn.

In de eerste plaats komt de rijksaccountant bij iedereen, grooten en kleinen, ongevraagd, om inzage te nemen van boeken en bescheiden, die kunnen dienen tot staving der aangifte of de nadere beweringen van den belastingplichtige. Dit zijn de boeken en bescheiden die aanwezig $z i j n$. Anders dan de public accountant, die aanwijzingen kan geven ter verbetering der administratie en ter verkrijging der noodige verdeeling van arbeid, die zijn taak in de toekomst kunnen vergemakkelijken, kan de rijksaccountant geen invloed oefenen op de administratie, die hij heeft te onderzoeken.

In de tweede plaats zou ik in verband met de kwestie van het opgewekt vertrouwen willen opmerken, dat een onvolledig onderzoek voor een bepaald doel voor een public accountant het groote bezwaar heeft. dat hij zijn rapport uit handen geeft en ondanks genomen voorzorgsmaatregelen het gevaar loopt dat men dit later buiten zijn voorkennis gebruikt, als ware het het resultaat van een volledig onderzoek.

Het is mij meermalen overkomen dat mij op een of andere wijze een balans in handen kwam, waarop de activa belangrijk hooger waren gewaardeerd dan op het in den legger aanwezige exemplaar. Men verklaarde dan uiteraard dat dit extra-exemplaar indertijd was opgemaakt, toen men een grooter crediet aanvroeg bij de Bank. Ik moet bekennen dat daardoor het opgewekt vertrouwen in beide exemplaren in ernstige mate werd geschaad.

m a b blz 422 
Aan dit gevaar staan de rijksaccountants niet bloot. Hunne rapporten zijn geheim en komen niemand in handen dan de betrokken belastingambtenaren. De Inspecteurs zijn voldoende op de hoogte van de omstandigheden waaronder het werk geschiedt om misverstand wat dat betreft te voorkomen en er bestaat uiteraard alle gelegenheid hen zoo volledig mogelijk in te lichten in geval van twijfel.

Eindelijk is het niet de taak van den rijksaccountant het controleeren van de boekhouding van de belastingplichtige, maar diens aangifte. Bij het controleeren van de aanwezige administratie heeft hij slechts te letten op dit doel. Het is niet zijn taak fouten, slordigheden of onvolledigheden in de administratie op te sporen en te verbeteren, indien dit niet noodig is voor de contrôle van de aangifte. Het kan zelfs voorkomen, dat hij er in slaagt door gebruik te maken van langs anderen weg verkregen gegevens de aangifte te controleeren en omissies in de administratie aan te toonen, die langs den directen weg van contröle der administratie aan de hand van de bescheiden moeilijk te ontdekken zouden zijn.

De heer Nye heeft bezwaar tegen de wijze waarop de rijksaccountant zijn arbeid verricht zooals de Heer de Blaey deze in korte trekken heeft uiteengezet. Zijn bezwaar is dat er van de contrôle der administratie weinig terecht komt en dat men zich bepaalt tot het nagaan of de cijfers aannemelijk zijn, en het doen van steekproeven, hetgeen op zich zelf reeds uit den booze is, inplaats van na te gaan of ze juist zijn.

Eendeels kan ik dit toegeven. Ook ik ben van meening dat dit een leemte is, zij het een leemte die onvermijdelijk is.

$\mathrm{Na}$ hetgeen ik heb betoogd, kan ik deze critiek niet afwentelen op de Overheid die te weinig personeel beschikbaar stelt of de accountants door te strakke banden bindt, al spreekt het vanzelf dat de Overheid den eisch zou moeten stellen dat eventueele aanvragen om meerder personeel verantwoord zijn.

De vraag is dus of het werk van den rijksaccountant verantwoord is. Men kan van meening zijn dat dit maar zeer ten deele het geval is en zelfs bevreesd zijn dat de naam van het accountantsberoep er door wordt geschaad, doch de opmerking op zich zelf verraadt reeds onvoldoende inzicht in het werk dat gedaan moet worden.

Over het algemeen kan men de zaken onderscheiden in kleine en groote. Er zijn natuurlijk kleine zaken met een uitstekende boekhouding, doch ook verscheidene waar de administratie alles te wenschen laat. Dit is niet te verwonderen, want de administratie geregeld zelf bij te houden. indien met den geheelen dag er op uit is om zijn zaken te drijven, is wel is waar voorgeschreven volgens het $W$. v. K. en wel zoo dat daaruit ten allen tijde zijn rechten en verplichtingen kunnen worden gekend, maar het is in den grond toch gansch niet eenvoudig. Gelukkig staat er nog bij naar den eisch van zijn bedrijf, hetgeen gemeenlijk geinterpreteerd wordt als, voor zoover zijn bedrijf dit toelaat.

Het controleeren van dergelijke administraties, die niet op contrōle zijn ingericht, is veel lastiger en kost veel meer tijd dan de public ac- countant, die over het algemeen te maken heeft met boekhoudingen door hem zelf ingericht, waar de bescheiden opgeborgen worden zooals hij het heeft voorgeschreven, zich meestal kan voorstellen. Bovendien zal de contrôle van zulk een administratie (men behoeft daarbij volstrekt nog niet aan kwade trouw, die echter ook voorkomt, te denken) in vele gevallen weinig resultaat opleveren. Men denke bijv. aan de contrôle van de administratie in de zaak bedoeld in de B.I.B. 6782, waarvan wordt

$\mathrm{m}$ a b $\quad \mathrm{blz} z_{\star} 423$ 
gezegd, dat het een eenvoudige enkele boekhouding was, dat ze gebrekkig was, daar ze fouten vertoonde, terwijl de dagontvangsten in één bedrag waren vermeld, waar men na contröle van de administratieve gegevens een aangifte van $f$ 2.500. - accepteerde, terwijl later na extracomptabele contrôle de aanslag op f 4.500. - werd vastgesteld.

In dergelijke gevallen heeft men nu eenmaal weinig steun te verwachten van de administratie op zich zelf en zijn er tamelijk nauwe grenzen getrokken wat betreft de bereikbare mogelijkheden. Contrôle oefenen op de goederenbeweging is uiteraard niet doenlijk, daar inventarissen meestal onbekend zijn en, indien al aanwezig, doorgaans totaal onvergelijkbaar zijn. Magazijnadministratie is een onbekend begrip, zoodat men aangaande de prijzen geheel in het duister tast. Daarbij worden de debiteuren in vele gevallen bij betaling nog steeds aileen maar doorgehaald, zoodat ook daarop, als ze al aan het begin en het einde van elk jaar zijn opgemakkt, weinig kans op een betrouwbare contrôle achteraf bestaat.

Toegegeven kan worden dat bij een uitgebreide contrōle van de administratie een groot aantal ongerechtigheden aan het licht zouden kunnen komen, die misschien onontdekt blijven. Met reden mag echter in dergelijke gevallen worden betwijfeld of zulk een onderzoek het resultaat zou hebben dat men dan wèl met gerustheid zou kunnen concludeeren dat de administratie na de correcties betrouwbaar is.

$\mathrm{Bij}$ groote zaken zijn de moeilijkheden van geheel anderen aard, maar daarom niet minder groot.

Zou men hier de administratie willen gaan controleeren dan zal men zich rekenschap moeten geven waar men aan begint. Zou men eenigszins afdoende te werk willen gaan dan komt het neer op een gratis accountantscontrôle van alle zaken in Nederland, hetgeen toch moeilijk de bedoeling kan zijn. Indien men de dagelijksche administratie zou willen betrekken in het onderzoek, dan zou dit toch waarschijnlijk wel zoo summier moeten geschieden dat het werken met steekproeven angstig dicht zou worden genaderd. Men vergete niet dat men heeft te controleeren in een vreemde zaak een boekhouding waarvan men niet op de hoogte is, dat men niet weet op welke wijze de interne contrôle werkt. zcodat men niet kan nagaan of deze werkelijk effectief is, dat men bovendien noch op de administratie, noch op de interne contrôle invloed kan oefenen. Zou men de dagelijksche administratie niet bij zijn onderzoek betrekken, dan valt niet in te zien hoe men met eenige zekerheid overtuigd kan zijn van de juistheid van de arbeid.

Hierbii moge men nog bedenken dat zoodra men de administraties der belastingplichtige zaken grondig zou willen onderzoeken, men wel gedwongen zou zijn het aantal te onderzoeken zaken te beperken, zoodat men dan zou komen tot een zeer vergaand en zeker ongewenscht steekproeven systeem, n.l. het onderzoeken van een zeer beperkt aantal zaken tegen het geheel onderzocht laten van de rest.

Op grond van het bovenstaande zou ik willen concludeeren dat een meer volledige contrōle der administratie bij de kleinere zaken niet zou bijdragen tot het verkrijgen van een belangrijk grootere zekerheid en dat dit bij de groote bedrijven niet mogelijk zou zijn.

Zejt nu de Heer Nye, dan verricht ge alleen adviseerend werk, dan ben ik bereid hem dat toe te geven. Of hij van meening is dat ook de rapporten van den rijksaccountant grooter vertrouwen trachten te wekken dan geoorloofd is en dat men door listige omschrijving van het doel van de opdracht een lastig voorbehoud tracht te ontgaan en zoo ja op wel-

m a b blz. 424 
ken grond weet ik niet. Over het algemeen zal juist de rijksaccountant weinig behoefte hebben, ,de doelstelling zoo te hervormen en te formuleeren dat de herleiding tot een beperkte doelstelling voor den niet deskundigen lezer onzichtbaar wordt". Zijn rapporten komen nu eenmaal niet onder de oogen van ondeskundige lezers, maar alleen van wat dat betreft zeker bevoegde Inspecteurs.

Ik zou er nog aan kunnen toevoegen dat de rapporten meermalen eindigen in een advies, zelfs wel in een advies de zaak na eenigen tijd nog eens in te zenden. omdat men niet zeker is van de juistheid van het gegeven advies, of omdat men er ditmaal niet in slaagde voldoende aannemelijk te maken dat de aangifte niet juist was.

Het moet mij echter van het hart dat ik het gemaakte onderscheid tusschen een advies en een conclusie van een rapport niet bijzonder kan waardeeren. Het lijkt mij eenigszins een woordenspel, als het resultaat hetzelfde blijft n.l. dat we verwachten dat het advies zal worden gevolgd.

In dit verband moge ik nog opmerken daa het den rijksaccountant niet mogelijk is, tenzij in bijzondere omstandigheden, het onderzoek af te breken. Het is duidelijk dat, ook wanneer het in een zaak niet mogelijk is tot een bepaald resultaat te komen, de rijksaccountant na het onderzoek in elk geval haar beter op haar merites kan beoordeelen dan de Inspecteur, die in zulk een geval toch geheel in het duister tast. Het komt mij voor dat men in elk geval een juiste aanslag dichter zal benaderen, al werd men er niet veel wijzer door, wanneer men bij het onderzoek een denkbeeld heeft gekregen van de omstandigheden waaronder de belastingplichtige leeft, van zijn persoon en van de waarde die men aan zijn administratie heeft te hechten, dan wanneer men zonder dat een beslissing moet nemen.

Welk gevaar er in zou schuilen en waarom men er niet in zou kunnen slagen door middel van steekproeven een denkbeeld te verkrijgen van de waarde die men aan een administratie mag toekennen is mij niet duidelijk. Men bemerkt toch al heel spoedig of de eerste aanteekeningen met zorg zijn bijgehouden of dat men er maar wat van heeft gemaakt, of men geregeld kas opmaakt, of dat er geregeld negatieve kassaldo's voorkomen, of men eenige waarde kan hechten aan de geboekte privéuitgaven, dan wel of men maar een rond bedrag geboekt heeft als het zoo uitkwam.

Die steekproeven kunnen wel degelijk resultaat hebben als het daardoor blijkt dat men wel eenig vertrouwen kan hebben in de gegevens voor de cijferbeoordeeling waartoe men zijn toevlucht moet nemen, daar men bijv. nu eenmal de ontvangsten in het kasboek voorkomende op geen enkele wijze kon controleeren. Die steekproeven kunnen zelfs met volstrekte zekerheid uitwijzen dat het geen zin zou hebben verder eenige waarde te hechten aan de geheele, op het kasboek, gebaseerde administratie.

Ik wil toegeven dat men zich in verschillende gevallen als rijksaccountant kan afvragen of men eigenlijk nu nog wel accountantswerk doet bij gebrek aan eene administratie waarop ook maar eenig peil is te trekken. In dergelijke gevallen is inderdaad weinig te verwachten van een boekenonderzoek. In vele gevallen echter slaagt men er wel degelijk in contrōle te oefenen, soms zelfs zeer scherpe contrōle. Door het verband na te gaan van het begin en het eindvermogen bestaat wel eens de mogelijkheid te constateeren dat omissies aanwezig zijn en zelfs aan te wijzen van welken aard deze zijn en vrij nauwkeurig de grootte ervan te bepalen. 
Hetzelfde kan geschieden door gebruik te maken van winstnormen, of renseignementen als anderzins.

In verschillende gevallen zal men er door zijn ervaring en intuitie geleid (men mag er niet op bouwen, maar ze bestaat) in slagen op zeer eenvoudige wijze een onaantastbaar lijkende administratie van zijn luister te berooven. Een bijzondere uitgave, de kosten van een nieuw gebouw kunnen blijken zoo groot te zijn geweest dat het bestaan van een geheime bankrekening er door aan het licht komt. Onregel matige boekingen kunnen gefingeerde betalingen aan den dag brengen, niet afloopende crediteuren eigen kapitaal. De praktijk wijst uit dat door nauwkeurig acht te geven allerlei tiscale ongerechtigheden aan den dag komen, daar het nu eenmaal veel minder eenvoudig is dan het lijkt in de administratie posten van eenig belang weg te werken zonder dat het bij aandachtig snuffelen opvalt.

Een gevaar dat de Heer Nije niet met zooveel woorden noemt, doch dat hem blijkbaar voor den geest zweefde is het volgende. Wanneer men niet in staat is volledig te controleeren, dan dreigt het gevaar dat men langzamerhand verslapt en zijn arbeid beperkt, omdat men toch geen bevredigend resultaat vermag te bereiken. Indien men het bedrag aan reiskosten, aan betaalde provisies, aan privé-uitgaven, aan toegestane geheime kortingen enz. enz. niet of niet voldoende kan beoordeelen dan is men geneigd zich er maar niet te veel van aan te trekken ook en het spoedig goed te vinden. Het is duidelijk dat indien men steeds en overal dergelijke vragen heeft te beoordeelen dit een latent gevaar meebrengt voor de waarde van de geleverde arbeid.

Dit kan eenerzijds leiden tot het wegmoffelen van dergelijke kwesties in de rapporten en anderzijds tot een soort vlucht in fiscale kwesties van meer of minder belang en tot wel eens te ver gaande correcties van afschrijvingspercentages enz, die de aandacht van de hoofdzaak afleiden.

Dit is de reden dat het over het algemeen goed kan zijn dat niet steeds dezelfde man dezelfde zaak onderzoekt, maar dat er geregeld afwisseling plaats vindt, waardoor vaak ongerechtigheden aan het licht komen, die vroeger onontdekt bleven.

Dit is ook de reden dat men niet zal en mag schromen in bepaalde gevallen, waar men twijfelt, een diepergaand onderzoek, dat vaak het volkomen onderzoek dicht nadert, in te stellen, zooals de heer de Blaey terecht opmerkte in zijn artikel.

Ik moet hierbij toch wel opmerken dat ook de public accountant dezelfde bezwaren moet ondervinden of weet hij wel waar de grens ligt tusschen geoorloofde reiskosten en familieuitstapjes en heeft hij de zekerheid dat hem alle geheime provisies worden meegedeeld en kan hij de winstpercentages wel precies beoordeelen? Want zou men daaraan moeten twijfelen dan zou de kans bestaan dat ook zijn verklaring grooter vertrouwen opwekt dan hij vermag te dragen, ook al is het contrôle plan, dat ten slotte toch ook wordt uitgevoerd door assistenten van vleesch en bloed, nog zoo goed doordacht en wetenschappelijk geheel verantwoord.

Men zou ook na deze uiteenzettingen toch van meening kunnen zijn dat, indien de accountant bij zijn onderzoek niet verder komt dan de conclusie dat de aangifte wel goed zal zijn, daar de cijfers niet onaannemelijk voorkomen, het beter ware dat, zoolang hij niet tot een meer positief resultaat komt, een accountant zich met dergelijke onderzoekingen niet inliet.

Het gevolg zou zijn dat of het werk achterwege werd gelaten of dat

m a b blz. 426 
het door anderen, minder bevoegd, zou worden verricht. Beide gevolgen zou ik ongewenscht achten.

In het eerste geval zouden de bepalingen van art. 70 en art. 74 der Wet I.B. een doode letter worden, daar de Inspecteurs uitsluitend zouden moeten afgaan op hetgeen hun kan blijken bij overlegging van boeken en bescheiden ter Inspectie. Hiervan is geen resultaat te verwachten, daar zelfs de meest scherpzinnige Inspecteur er niet in kan slagen ter Inspectie in den korten tijd die voor een oproeping beschikbaar is, iets positiefs te weten te komen aangaande bepaalde cijfers van de overgelegde boekhouding. Het is overigens onaannemelijk dat men thans, nu zulke exhorbitante eischen aan de schatkist worden gesteld, en de Belastingen tot het tegenwoordige peil zijn opgevoerd, daaraan zou kunnen denken.

Het tweede geval, dat het werk door minder bevoegden zou moeten geschieden, zou niet minder te betreuren zijn. Het staat toch vast dat het werk speciale accountantseigenschappen vergt. Degenen, die er mee belast zijn moeten beschikken over een goeden kijk op cijfers en een scherp critisch onderscheidingsvermogen, over veel initiatief en strijdvaardigheid. $Z_{i j}$ zullen met gezag moeten kunnen optreden en toch voldoende tact hebben om zonder ongewenschte strubbelingen voet bij stuk te houden. Ze moeten gebruik weten te maken van zeer verschillende middelen, al naar mate de soort zaak waar zij hun onderzoek verrichten en de personen waarmede zij te maken hebben. In het kort ze moeten niet in naam. maar metterdaad accountant zijn. Steeds hebben wij gepropageerd dat de daarvoor benoodigde kennis iemand niet komt aanwaaien, doch gestage studie vereischt. Dit in aanmerking nemende, geloof ik te mogen zeggen dat het toch wel zeer kortzichtig zou zijn, indien men zulk werk zou overlaten aan onbevoegden, die er zeker minder van terecht zouden brengen dan de accountants en de adjunct-accountants, welke laatsten in het algemeen gesproken studeeren voor accountant.

Hierbij zou ik het willen laten. Ik hoop er in geslaagd te zijn aannemelijk te maken:

1. dat de rijksaccountant zijn arbeid verricht minstens even onafhankelijk als zijn collega in het vrije beroep.

2. dat indien hij niet steeds zoover gaat met zijn contróle als wel gewenscht lijkt dit geschiedt op gronden van vak-technischen aard, bepaald door de omstandigheden waaronder hij zijne arbeid verricht,

3. dat die arbeid hooge eischen stelt, niet alleen aan zijn persoon, maar ook aan zijn bekwaamheid en zijn geschiktheid om als accountant op te treden,

4. dat zijn werk ook zooals het geschiedt een niet te vervangen schakel is in de arbeid van den fiscus om te trachten de aanslagen zoo juist mogelijk op te leggen, waardoor niet alleen een aanwijsbaar direct resultaat wordt behaald maar waarvoor bovendien ongetwijfeld een groote preventieve werking wordt ondervonden, waardoor een groot sociaal belang wordt gediend.

\section{Naschrift}

Ter vermijding van misverstand wil ik - wellicht ten overvloede vooraf opmerken, dat ik erken,

1e. het nut en de gerechtvaardigdheid van den arbeid van den rijksaccountant en de wijze, waarop hij werkt. Zijn werk is voor de gemeenschap van groot nut. 
Met punt vier van de conclusies, waartoe de Heer Hageman komt. kan ik mij dus vereenigen;

2e. dat de wegen, langs welke de rijksaccountant een aangifte verifieert (winstnormen, renseignementen) vaak veel effectiever zijn dan een onderzoek van de administratie, (mede als gevolg van het feit, dat de administratie in niet-controleerbaren vorm wordt gehouden);

3e. dat het werk van den rijksaccountant speciale eigenschappen eischt, welke alleen worden verkregen door een opleiding tot accountant en dat vele dezer eigenschappen dezelfde zijn, welke de public accountant moet hebben.

Met het derde punt der conclusies ga ik dus ook accoord.

De tweede conclusie lijkt mij echter te ver te gaan. De contrôle gaat volgens collega Hageman minder ver dan wel gewenscht lijkt:

1e. omdat tal van administraties

a. absoluut geen steun geven voor de contrôle, omdat zij onvoldoende zijn ingericht,

b. na eenige "steekproeven" geen vertrouwen wekken;

2e. omdat bij groote zaken een uitgebreidere contrôle gratis contrôle zou beteekenen en als eenig alternatief zou blijven het aantal te onderzoeken zaken sterk te beperken.

In gevallen, genoemd in het eerste punt zou m.i. de public-accountant de opdracht als contrôle-opdracht moeten weigeren. Zoo'n zaak is niet te controleeren. Hij kan hoogsten op grond van een berekening, gebaseerd op normen, een advies geven omtrent de mogelijke cijfers. Deze onderscheiding in ",advies" en "contrôle" is geen woordenspel, maar een principieele onderscheiding.

Hoezeer het woord ",contrôle" hier misplaatst is, blijkt wel uit het arrest B.i.B. 6782, waarin door den H.R. van ,contrōle" wordt gesproken, zonder vermelding, dat dit een beperkte contrôle, of een ",advies" was.

Indien de rijksaccountant in dit geval duidelijk had laten uitkomen, dat hij niet heeft gecontroleerd, doch op grond van een normenberekening adviseert de inkomsten op $f 2500$. - te schatten, dan had nooit in het arrest het woord "contrôle" kunnen voorkomen. Nu het tegendeel is geschied, leeft de Inspecteur en met hem de R. v. B. en de H.R. in de veronderstelling, dat er is gecontroleerd. Een bewijs voor mijn stelling, dat zelfs in beperkten kring de beperkingen inhoudende verklaring een te groot vertrouwen wekt. Immers voor een ",beperkte contrôle" behoeft de accountant zich niet ,,onder alle omstandigheden" „te begeven in een nasporen en waardeeren van alle gegevens" en voor een advies evenmin. Doch voor een ",contrôle" zonder meer is deze stelling toch absoluut onjuist.

Uit het door mij in dit onderschrift onder 2 genoemde blijkt duidelijk, dat geen vak-technische bezwaren een diepergaande contrỏle verhinderen, maar economische overwegingen van den opdrachtgever. Hoe begrijpelijk en gerechtvaardigd deze ook mogen zijn, gaat het toch te ver om deze overwegingen te rangschikken onder die van vaktechnischen aard!

Thans de eerste conclusie van den Heer Hageman. Deze is gebaseerd op zijn uiteenzetting omtrent het initiatief, de zelfstandigheid en de verantwoordelijkheid van het Hoofd van den Dienst en de onder hem ressorteerende accountants en adjunctaccountants.

Ik wil aanstonds vaststellen, dat ik bij mijn uiteenzetting omtrent de functie van den accountants-beambte de principieele punten zeer sterk

$\mathrm{m}$ a b blz。 428 
naar voren heb gebracht en daardoor den indruk heb kunnen wekken, als zou ik daarbij het oog hebben gehad op den aan den leiband loopenden. uitsluitend volgens voorschriften handelenden ambtenaar. Het tegendeel is echter waar. In principe is weliswaar ieder, die in dienstbetrekking is, gehouden volgens de voorschriften van zijn werkgever te handelen, doch van geval tot geval kan de mate, waarin dit practisch het geval is, sterk verschillen. Hoe dit ook $z \mathrm{ij}$, bij de grootst mogelijke vrijheid van den accountant-beambte blijft in principe de leider der organisatie, warin hij werkt, bevoegd de taak van den accountant-beambte - los van de bepalingen van het reglement van arbeid - te vervormen of te beperken. Hierop is slechts één uitzondering t.w. indien in de arbeidsovereenkomst de leider der organisatie i.c. de Secretaris Generaal van het Departement uitdrukkelijk afstand van dit recht zou hebben gedaan. Zou dit voor het Hoofd van den Dienst het geval zijn, dan heeft de Heer Hageman het pleit gewonnen. Voorzoover mij bekend behoudt de rijksaccountant en dus ook het Hoofd van den Dienst zich dit recht echter bij zijn aanstelling niet voor.

Uiteindelijk is hier van belang de positie van het Hoofd van den Dienst. De onder het Hoofd van den Dienst staande accountants en adjunctaccountants mogen dan al hun arbeid ten opzichte van het Hoofd van den Dienst even onafhankelijk verrichten als hun collega's in het vrije beroep, het Hoofd van den Dienst is tenslotte gedwongen de werkzaamheden te regelen niet naar vaktechnische eischen, maar naar het aantal menschen, dat hem van hoogerhand ter beschikking wordt gesteld. Hetgeen de Heer Hageman betreffende de groote zaken opmerkte, wijst duidelijk in deze richting. De rijksaccountant blijft dus m.i. te rangschikken onder de ,accountants-beambte" en vervult dientengevolge een andere functie dan de public-accountant.

De Heer Hageman heeft door zijn artikel de wellicht door de voorafgaande discussie gewekten indruk, dat de rijksaccountant een zeer onzelfstandige positie zou innemen, weggenomen, doch heeft mij niet kunnen overtuigen, dat mijn uitgangspunt (de rijksaccountant heeft een andere "Functie" dan de public-accountant) onjuist zou zijn. Mijn op deze stelling gebaseerde bezwaren tegen de formuleering van het arrest van den Hoogen Raad en mijn voorloopige conclusies t.a.v. de verdeeling van het terrein van arbeid tusschen de accountants-beambte en de public-accountants zijn daardoor in wezen onaangetast gebleven.

D. NIJE

\title{
REGELING VAN HET BEDRIJF VAN AAN BANKEN VER- WANTE FINANCIEELE INSTELLINGEN IN FRANKRIJK
}

\author{
door Dr. H.W. J. Wijnholds
}

In een vorig artikel 1) bespraken wij de eenige maanden geleden ingevoerde Fransche bankwet. Daarbij werd er reeds op gewezen, dat in deze wet niet alleen het bankwezen werd geregeld, doch dat daarin ook bepalingen voorkomen met betrekking tot beroepen, die aan dat van bankier verwant zijn. De voorschriften voor de laatstgenoemde groep van

1) Maandblad voor Accountancy en Bedrijfshuishoudkunde, October 1941. 